\title{
EREBEA
}

Revista de Humanidades

y Ciencias Sociales

Núm. 6 (2016), pp. 273-285

ISSN: 0214-0691

\section{OrgaNIZACIÓN ESPACIAL DE LA ARQUITECTURA RELIGIOSA POSTRIDENTINA: EL CONFESONARIO EN ALGUNOS EJEMPLOS ESPAÑOLES}

\author{
Rafael Cómez Ramos \\ Universidad de Sevilla
}

RESUMEN

Este artículo trata sobre el impacto de los decretos del Concilio de Trento en la transformación del espacio de la arquitectura eclesiástica a través del confesonario, haciendo referencia a ciertos ejemplos espańoles.

\section{Palabras Clave}

Arquitectura barroca; Concilio de Trento; Confesonarios; Arquitectura barroca en Espańa.

Fecha de recepción: 20 de abril de 2016 Fecha de aceptación: 29 de junio de 2016

\section{Abstract}

This paper deals with the impact of the Council of Trenton the space and function in ecclesiastical architecture of confessionals. Reference is made to several Spanish examples.

\section{KEYWORDS}

Baroque Architecture; Council of Trent; Confessionals; Baroque Architecture in Spain.

* Este artículo es la ampliación y puesta al día, con su correspondiente aparato crítico, de la conferencia impartida en el Auditorio Municipal de Portel (28 de septiembre de 2012) dentro del Coloquio Poderes, arquitecturas e evangelização. A construçao de uma nova paisagem em Portel (séculos XVI a XVIII). 

El propósito de este artículo es destacar la importancia de un elemento del equipo litúrgico de la arquitectura eclesiástica susceptible de ser construido en madera y cuya estructura contribuye a transformar el espacio arquitectónico como es el confesonario. Nunca ponderaremos lo suficiente el papel trascendental de la Iglesia católica, medio conservador, por excelencia, en la investigación, descubrimiento y difusión de grandes creaciones artísticas puestas al servicio de la liturgia desde los días de la Edad Media. Creaciones que llegarán a su culminación con los Papas del Renacimiento y que, finalmente, se transformarán, depurándose en los años posteriores al Concilio de Trento al convertir la herencia medieval de un arte teológico en un arte antropológico, por así decirlo ${ }^{1}$.

La Contrarreforma supuso un notable incremento en la construcción de iglesias y a partir de 1563 se produjo un asombroso aumento en su edificación, tras la publicación de las actas del Concilio de Trento. En pocos momentos de la historia de la Iglesia se ve reflejada con mayor claridad la importancia de la liturgia en la transformación del espacio arquitectónico sagrado ${ }^{2}$. En esta coyuntura, como bien afirmaba Paul Frankl, la iglesia es "un espacio para misas, confesiones y sermones"3 (Fig. 1). Por tanto, los sermones y las confesiones darán lugar a la creación de algunos de los objetos arquitectónicos más singulares, extraordinarios y espectaculares del mobiliario sagrado: los púlpitos y los confesonarios. Es en estos últimos en los que vamos a detenernos para demostrar el impacto de la normativa de los decretos conciliares en la organización espacial postridentina y el discurso iconográfico de los templos.

1 R. Pernoud, Las grandes épocas del arte occidental, Buenos Aires: Librería Hachette, 1959, pp. 237-238. Esta diferencia es semejante a la establecida entre la imagen de culto medieval y la imagen de devoción moderna por R. Guardini, Imagen de culto e imagen de devoción. Sobre la esencia de la obra de arte, Madrid: Guadarrama, 1960, p. 17, que ahora cobra otra dimensión en la obra de H. Belting, Imagen y culto: una historia de la imagen anterior a la edad del arte, Madrid: Alianza, p. 5.

2 A. Rodríguez G. de Ceballos, "Liturgia y configuración del espacio en la arquitectura española y portuguesa a raíz del Concilio de Trento", Anuario del Departamento de Historia y Teoría del Arte, UAM, Madrid, Vol. III, 1991, pp. 43-52.

3 P. Frankl, Principios fundamentales de la Historia de la arquitectura. El desarrollo de la arquitectura europea: 1420-1900, Barcelona: Gustavo Gili, 1981, p. 231. 


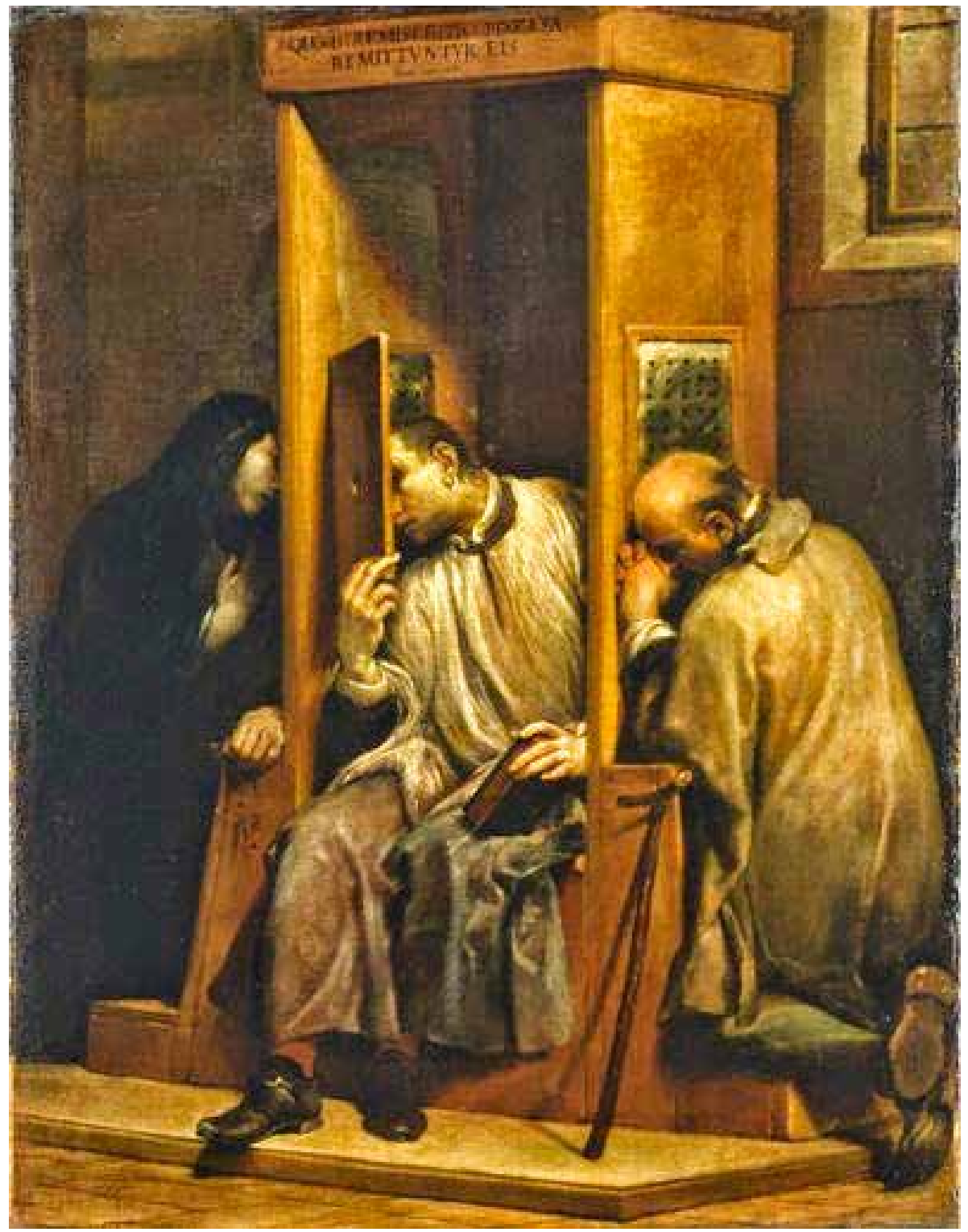

Fig. 1. Giuseppe María Crespi, "Confesión de la reina de Bohemia”, Galleria Sabauda, Turín. 
En principio, la confesión se practicaba públicamente, pero según un relato de san Juan Clímaco esta modalidad de pedir perdón de los pecados resultaba muy enojosa por la repugnancia que experimentaban no sólo los pecadores sino también los confesores, por lo que, finalmente la penitencia pública se convirtió en penitencia privada prevaleciendo el secreto de confesión ${ }^{4}$. Una simple silla colocada en el atrio de la iglesia cumplió dicha función y aun cuando la penitencia pública había caído en desuso y los pórticos de las basílicas no estaban repletos de penitentes como en los siglos IV y V, los concilios de Worms (868), Maguncia (888), y Casel (1172) demuestran que ciertos aspectos de esa modalidad perduraron hasta fines del siglo XII ${ }^{5}$. Finalmente, el concilio de Tarragona (1242) trata de tres clases de penitencias que se realizan durante siete o diez ańos, según el pecado, en la catedral o en las parroquias: “... acudirán a la catedral o a la iglesia parroquial, y en el mismo traje, y serán expelidos de la iglesia, permaneciendo fuera de ella toda la cuaresma; acudiendo sin embargo a las puertas de la iglesia para oír desde allí el oficio ${ }^{6}$.

Por otra parte, se mantuvo ciertamente la penitencia privada pues no todos los pecadores en la Edad Media eran parricidas, fratricidas o conversos, y como prueban muchas fórmulas del Confiteor que recitaba el penitente, la frase "Confiteor... coram hoc altari sancto" indica que la confesión tenía lugar delante de un altar, posiblemente alguno de los situados en las capillas laterales ${ }^{7}$. No obstante, la existencia de estos sillones o sillas portátiles en la Baja Edad Media comienzan a usarse ya las primeras cátedras penitenciales, fijas, abiertas y arrimadas al muro de la iglesia como podemos observar en algunas estampas y pinturas murales ${ }^{8}$, y que pueden considerarse el antecedente directo de los actuales confesonarios.

La prohibición de administrar la confesión fuera de la iglesia, o en casas particulares, que queda patente en el Concilio de Sevilla (1512), donde se dieron

4 Scala Paradisi, gradus IV, P. G., t. LXXXVIII, col. 681-684; F. Cabrol, H. Leclercq, Dictionnaire d'Archéologie Chrétienne et de Liturgie, t. XIV, 1, Paris, 1939, col. 200-202.

5 Los Sacrosantos Concilios generales y particulares, trad. de C. Richard, Madrid, 1793-1796. Véase I. Bango, "Atrio y pórtico en el románico español: concepto y finalidad cívico-religiosa", Boletin del Seminario de Arte y Arqueología, Valladolid, 1975, p. 183-184.

6 I. Bango, op. cit., p. 184.

7 M. Righetti, Historia de la Liturgia, I, Madrid: BAC, 1955, p. 434; G. Durandus, Rationale Divinorum Officiorum, Lib. I, traducción en S. Sebastián, Mensaje del arte medieval, Córdoba, 1978, apéndice pp. 2-46.

8 M. Righetti, op. cit.,I, p. 436 y II, p. 681. El primer testimonio gráfico de un confesonario aparece en la obra Devotus libellus de modoconfitendi et poenitendi, Delft, 1494, y los primeros confesonarios murales se encuentran en Pisa en el siglo XIV. Véase también R. Cómez, Arquitectura y feudalismo: los comienzos del arte novohispano del siglo XVI, México: UNAM, 1989, fig.70. En la iglesia de Santa María de Nápoles existe una representación de un confesor pintado al fresco, posterior a 1350, atribuido por Vasari a Giotto, y actualmente a Oderisio. Cf. A. Chastel, Italian Art, Londres: Faber and Faber, 1972, p. 116. 
observaciones acerca de los confesonarios portátiles y movibles ${ }^{9}$, así como las prescripciones del Concilio de Valencia (1565) que ordena que se construyan confesonarios en sitios aptos y patentes "para confesar en especial a mujeres" ${ }^{10}$, y las instrucciones dadas en el Concilio de Toledo (1582), que manda que sean abiertos "de modo que entre el confesor y la penitente se interponga por honestidad una lámina de hierro o un enrejadito" ${ }^{11}$. Estos preceptos se justifican en razón de la relajación del clero pues, a continuación, en el capítulo XXIX, se prescribe: "Pena de los confesores que tiene cópula carnal con mujeres, cuyas confesiones hubieren oído", lo cual refleja una tendencia general a separar y evitar todo contacto entre el sacerdote y la mujer, induciéndonos a pensar que estos confesonarios murales hayan sido construidos no únicamente, pero sí especialmente, con finalidad de administrar el sacramento de la penitencia a la mujer.

Así pues, el confesonario consistente en la horadación del muro de la iglesia en cuyo espacio se sienta el confesor mientras el penitente acude por el otro lado, abriéndose entre ambos una ventanita con celosía, viene a representar una modalidad propia de conventos y monasterios de Extremadura, Andalucía y México ya que el sacerdote acudía desde el claustro y los fieles desde el templo o viceversa en los conventos de monjas sin que se vieran más que el rostro a través de la celosía, y al mismo tiempo, la concreción pétrea de aquellas cátedras penitenciales de los siglos XIV y XV, que se habían arrimado paulatinamente a los muros de las iglesias.

Este tipo de confesionario instalado dentro del macizo del muro participa de la celosía o rejilla, que se interpone a los rostros del confesor y el penitente, prescrita por el Ritual Romano, que emana de las directrices renovadoras del espíritu de Trento y recuerda que en la Edad Media en ciertos lugares se interpuso un velo entre el confesor y las mujeres, pues en las Constituciones (1235) de san Edmundo, arzobispo de Cantorbery, se lee: "Velum quidem quantum ad visum, non quantum ad auditum" ${ }^{12}$. Sin embargo, este género de confesonarios

9 Colección de cánones y de todos los concilios de la iglesia Española, traducido por J. Tejada y Ramiro, Madrid, 1855, V, p. 86: Concilio de Sevilla (1512), XIX, "Qué debe observarse acerca de los confesonarios y altares portátiles o móviles". Sobre el Concilio Provincial de Sevilla, celebrado bajo el episcopado de fray Diego de Deza véase D. Ortiz de Zúñiga, Anales eclesiásticos y seculares de la ciudad de Sevilla, Madrid, 1794, III, pp. 283-284; J.A. Morgado, Prelados sevillanos o episcopologio de la S.I.M. de Sevilla, Sevilla, 1906, p. 397, y J. Sánchez Herrero, "La Sevilla del Renacimiento" en J. Sánchez Herrero (Coord.), Historia de las diócesis españolas, 10. Iglesias de Sevilla, Huelva, Jerez y Cádiz y Ceuta, Madrid: BAC, 2002, pp. 152-154.

10 Colección de cánones... V, p. 276: Concilio de Valencia (1565), XVII, "Se erigirán sitios a propósito para oír confesiones"

11 Colección de cánones...op. cit., V, p. 469, Concilio de Toledo (1582), XXVIII: "De qué manera han de hacerse los confesonarios".

12 M. Righetti, Historia de la Liturgia, II, p. 861. Véase también J. Ferrando Roig, Normas eclesiásticas sobre arte sagrado, Barcelona: Montaner y Simón, 1940, pp. 70-71. 
al difuminarse entre los muros del templo no haciéndose visible a primera vista -pues se confunden con una pequeña puerta-se relacionan con los confesonarios medievales, que no eran ostensibles en las naves y se dispersaban por rincones y capillas, ya que lo propio del confesonario barroco es su evidencia plástica y corporeidad, ocupando un lugar conspicuo del espacio sagrado.

\section{II}

Una de las características de la segunda fase del desarrollo de la arquitectura europea (1550-1700), según Frankl, es la subordinación de los intereses artísticos a los religiosos en el sentido de que el desplazamiento de los ideales del humanismo por la Contrarreforma se refleja, en el campo de la arquitectura, en el predominio de los intereses litúrgicos sobre los puramente artísticos ${ }^{13}$. Así pues el interior del templo se enriquecerá con suntuosos altares destinados a la celebración de la misa y adquirirá una nueva dimensión, dada la importancia de los sermones y del sacramento de la penitencia, con los púlpitos y confesonarios. Los confesonarios van a equipararse a las sillerías de coro no sólo en cuanto a decoración sino también por ocupar ya un lugar fijo en el espacio de la iglesia.

El "deus ex machina" de esta transformación del espacio eclesiástico en función de la liturgia fue el cardenal y arzobispo de Milán, sobrino de Pío IV, san Carlos Borromeo, quien participó activamente en el Concilio de Trento, velando por los aspectos litúrgicos y de disciplina eclesiástica referente a los edificios ${ }^{14} \mathrm{y}$ cuyas Instrucciones sobre la administración del sacramento de la Penitencia prescriben que el sacerdote "tendrá en la Iglesia un Confesonario señalado, en que oiga las confesiones: habrá dos confesonarios, en donde los feligreses lleguen a quinientos; y muchos más en donde hay más Confesores; cuyos Confesonarios estarán en lugar patente y público de la Iglesia, y no en los rincones del Templo, o de alguna Capilla"15.

Es decir, Carlos Borromeo establece el número de confesonarios en función del número de fieles que tiene cada iglesia, disponiendo que se coloquen en lugares destacados del templo para evitar su dispersión en cualquier otro espacio que no sea la nave principal, prohibiendo su ubicación en capillas o sacristías, como había ocurrido en la Edad Media. Por otra parte, la prescripción del uso de la cátedra penitencial, cerrada por dos lados y con una rejilla metálica entre

13 P. Frankl, Principios fundamentales de la Historia de la arquitectura, pp. 227-230.

14 Carlos Borromeo, Instruccionum fabrica eecclesiasticae (1580), lib. II, cap. XXIII. Sobre el Concilio de Trento y las artes véase R. Wittkower, Arte y Arquitectura en Italia, 1600-1750, Madrid: Cátedra, 1979, pp. 21-23 y A. Blunt, Teoría de las artes en Italia: 1450-1600, Madrid: Cátedra, 1987, p. 115 y ss.

15 Carlos Borromeo, Avvertimenti di San Carlo per li confessori, $3^{\mathrm{a}}$ ed., Roma, 1702, trad. F. Lázaro del Hortal, Madrid, 1768, pp. 66-67. Sobre el sacramento de la penitencia véase El sacrosanto y Ecuménico Concilio de Trento, trad. por I. López de Ayala, 2a ed., Madrid, 1785, pp. 192-223. 
el confesor y el penitente, quedaría consagrada a partir de la adopción del Ritual Romano en 1614, donde cristalizaron convirtiéndose en norma los preceptos de la doctrina de Trento ${ }^{16}$.

En otras palabras, esta segunda fase del desarrollo de la arquitectura europea en la que se desenvuelven los estilos manierista y barroco representa en cuanto al mobiliario arquitectónico - con los colosales confesonarios corridos de Santa María Himmelfahrt en Colonia y san Pablo en Amberes - no sólo la antítesis y superación de la fase anterior sino su culminación pues, con anterioridad, no conocemos confesonarios de valor artístico. Como colofón de esta fase, los confesores tendrán su santo patrón en San Juan Nepomuceno, mártir del secreto de confesión ante el rey Wenceslao IV de Bohemia que mandó cortarle la lengua y arrojarlo al río Moldava desde el puente de Praga en 1393, siendo canonizado en $1729^{17}$.

\section{III}

El mejor ejemplo de la arquitectura contrarreformista es el Gesú de Roma. No ha habido una iglesia cuya planta haya sido más difundida y haya ejercido más influencia que ésta de Giacomo Vignola (1507-1573) diez años después del Concilio de Trento. De una manera sumamente original, este arquitecto supo combinar el espacio longitudinal de origen medieval con el espacio centralizado del Renacimiento, solución que Alberti había adoptado un siglo antes en la iglesia de San Andrés de Mantua.

También Vignola adopta la solución de Alberti al tratar las naves laterales como una secuencia de capillas que abren a la nave principal. La inmensa anchura de la nave principal convierte a las capillas en algo así como nichos que abren a un salón. Se ha hablado de la tradición gótica española representada por la iglesia catalana de Santa María de Montserrat en Roma $(1495)^{18}$. Lo cual significaría una vez más un ejemplo de la renovación y purificación de los ideales de la Edad Media, como ocurre también, por ejemplo, en la iconografía al retomar temas de la Baja Edad Media, como es el caso de la figura de San José o la del Ángel de la Guarda ${ }^{19}$. Sin embargo, una iglesia medieval no tendría nunca la luminosidad del Gesú.

16 RitualeRomanum, Can. 909, par. 2: "habeant in ecclesia sedem confesionalem, in qua sacras confessiones excipiat, quae sedes patenti, conspicuo et apto ecclesiae loco posita, crate perforata inter poenitentem et sacerdotem, sit instructa". Para aspectos generales del Concilio de Trento véase R. García Villoslada, Historia de la iglesia en España, III, $1^{\circ}$ y 2º Madrid: BAC, 1980.

17 D. Hugh Farmer, The Oxford Dictionary of Saints, $3^{\mathrm{a}}$ ed., Oxford: Oxford University Press, 1992, p. 264.

18 N. Pevsner, Esquema de la arquitectura europea, 2a ed., Buenos Aires: Ediciones Infinito, 1968, p. 216.Véase también R. Wittkower e I. Jaffe, Baroque Art. The Jesuit Contribution, Nueva York, 1972.

19 É. Mâle, El arte religioso del siglo XII al siglo XVIII, 2a ed., México: FCE, 1966, pp.179-181. 
La luz entra a través de ventanas situadas encima de las capillas de una manera difusa y suave, preparándonos para el impacto del luminoso crucero con la grandiosa cúpula horadada por los huecos del tambor, de un modo semejante a la decoración que ornamenta la superficie de los muros: tenue y lujosa al mismo tiempo, aunque no corresponde ya a la época de Vignola, pues se realizó en pleno Barroco, entre 1668 y 1683.

Ejemplos de la influencia de esta planta en España dentro del ámbito castellano serán la iglesia de la Clerecía de Salamanca, perteneciente al Colegio Real de los jesuitas, proyectado para dar cabida a 300 padres,cuyas trazas son de Juan Gómez de Mora (1617), dotándola de trascoro para la comunidad y transacristía ${ }^{20}$ (Fig. 2). Por otra parte, la iglesia del Colegio Imperial de los jesuitas en Madrid, luego catedral de San Isidro, comenzada en 1622 sobre planos del hermano Pedro Sánchez, y continuada después por el hermano Francisco Bautista ${ }^{21}$.

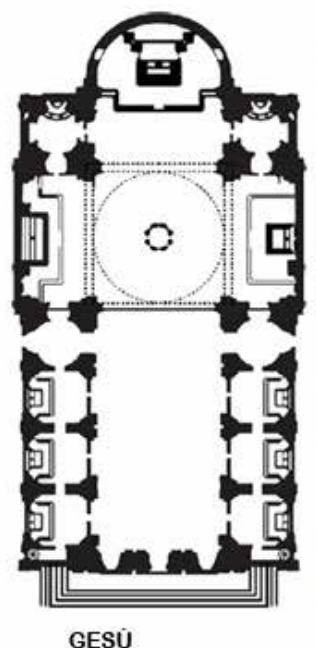

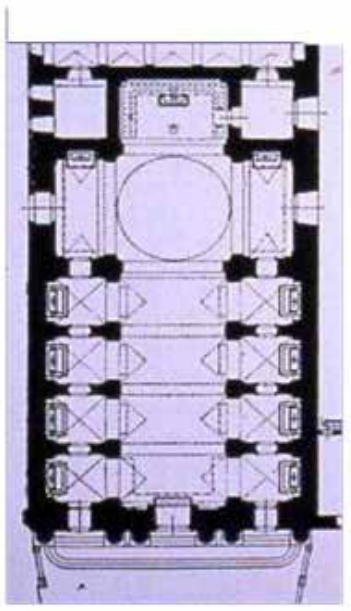

CLERECIA

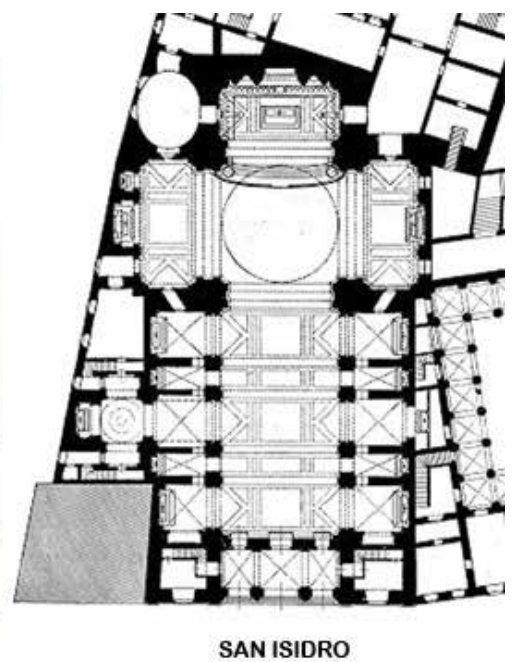

Fig. 2. Plantas de las iglesias del Gesú (Roma), la Clerecía (Salamanca), catedral de San Isidro (Madrid).

En el ámbito andaluz contamos con un buen ejemplo de las que Kubler denominó "iglesias en forma de cajón" en la iglesia del sagrario de la Catedral de Sevilla, comenzada por Miguel de Zumárraga en 1615 y no concluida

20 G. Kubler, Arquitectura de los siglos XVII y XVIII, "Ars Hispaniae", XIV, Madrid: Editorial Plus Ultra, 1957, pp. 51-52.

21 G. Kubler, op. cit., pp. 60-61. 
hasta $1662^{22}$ (Fig. 3). Otro ejemplo sería la iglesia del convento de los Clérigos Menores -orden fundada en Nápoles por San Francisco Caracciolo en 1588, actual parroquia de Santa Cruz en Sevilla, comenzada en 1655 y terminada, finalmente, en $1728^{23}$. Todos estos ejemplos españoles contaban con hermosos púlpitos y confesonarios que se solían ubicar ante los pilares que conformaban las capillas laterales, como ocurre en las iglesias del Gesú en Roma y de San Miguel en Munich.

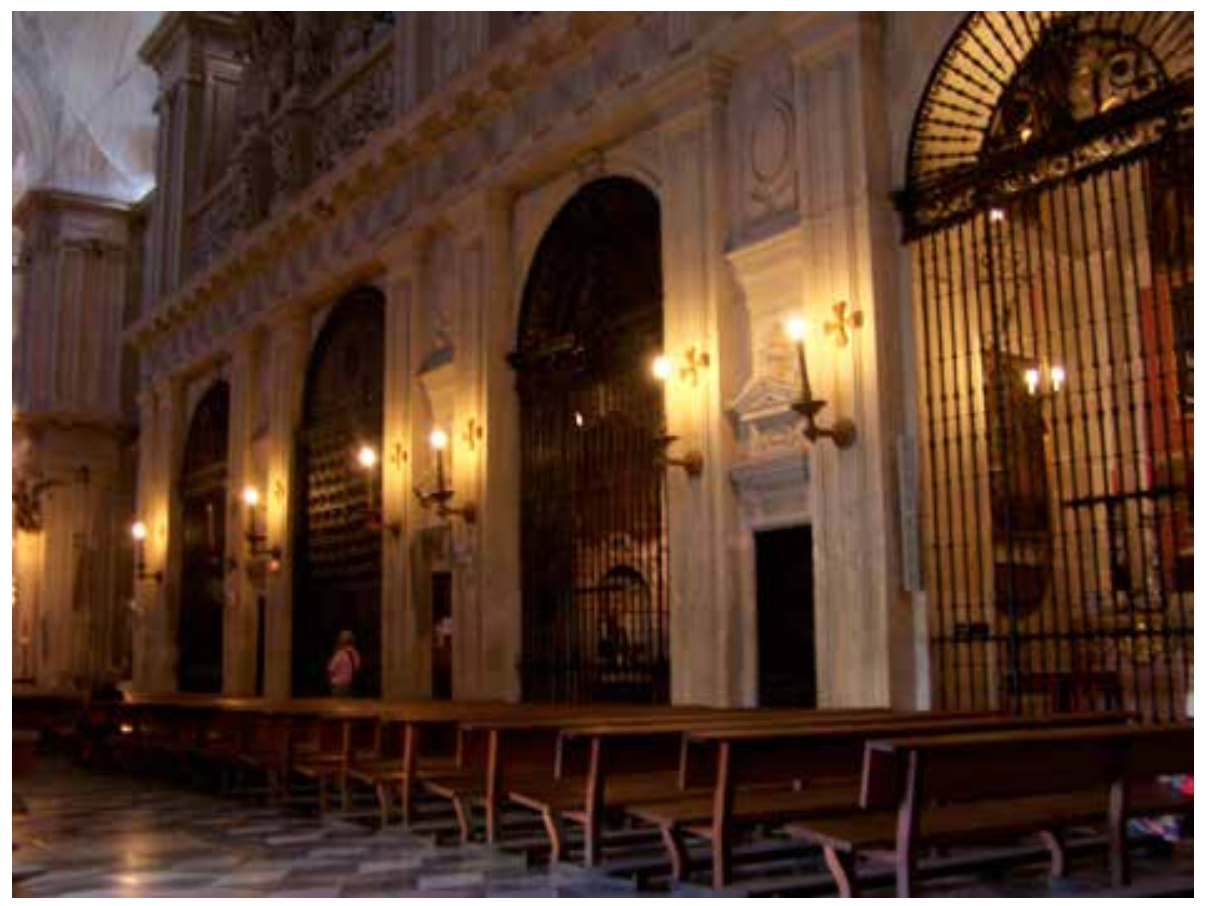

Fig. 3. Iglesia del Sagrario de la catedral de Sevilla.

22 G. Kubler, íbidem, pp. 26-29. Véase también T. Falcón, La iglesia del Sagrario de la Catedral de Sevilla, Sevilla: Diputación Provincial, 1977; A. Sancho Corbacho, Descripción de la parroquia de San Clemente o del Sagrario de la Catedral y Catálogo de sus obras de arte, Sevilla 1981; E. Gómez Piñol y Ma Isabel Gómez González, El Sagrario de la Santa Iglesia Catedral de Sevilla, Madrid: Iberdrola, 2004.

23 M. Fernández Rojas, "El convento del Espíritu Santo de Sevilla, vulgo de los Menores, de la orden de Clérigos Regulares Menores", Laboratorio de Arte, 19 (2006), pp. 195-214. 
Respecto a este mueble tan expresivo del espíritu de la Contrarreforma y que representa un elemento más a tener en cuenta dentro de la conformación espacial del templo barroco (Fig. 4), hemos de considerar los textos preceptivos de san Carlos Borromeo, cardenal y arzobispo de Milán, y sobrino del pontífice Pío IV, que lo define de esta manera, después de tratar sobre el facistol y el púlpito:

"Esta es la forma, de acuerdo con lo prescrito, de la cual deberá construirse el confesonario; habiéndola observado, se podrá emplear además algunos ornamentos, como las cornisas elaboradas en la parte anterior u otro género de ornato decente".

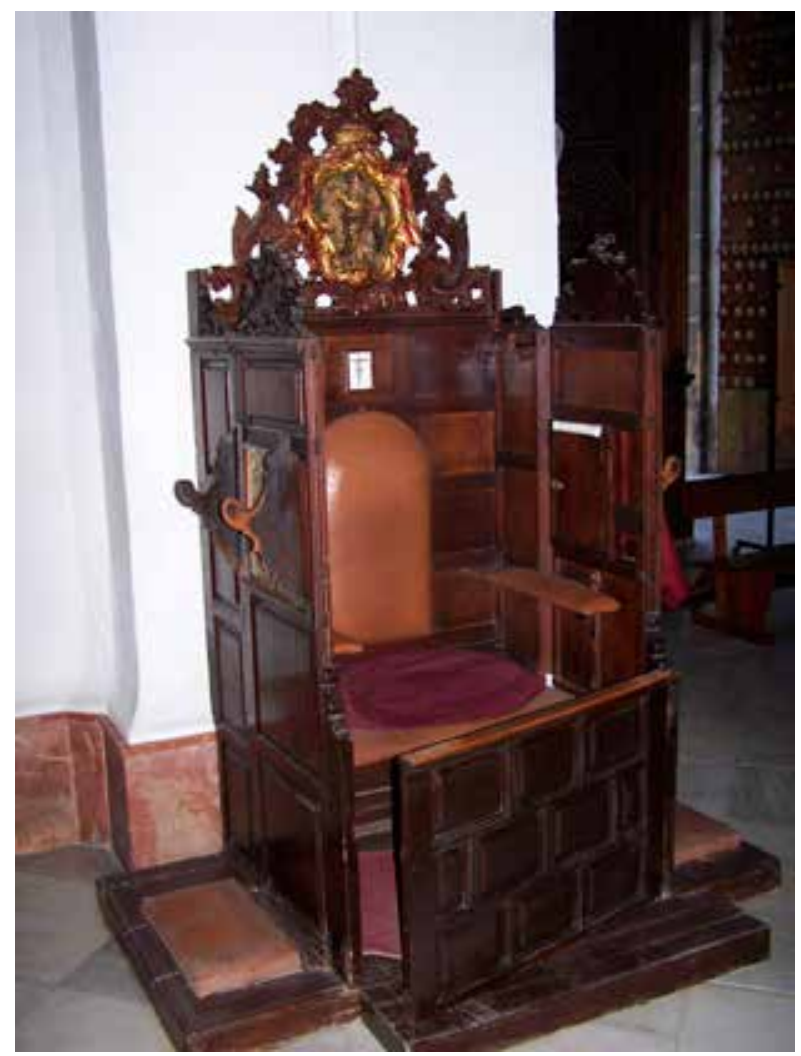

Fig. 4. Confesonario de la iglesia de Santa Cruz de Sevilla.

"Primeramente sea todo de tablas taraceadas, o de nogal, o ciertamente de otro cualquier género; cercado naturalmente con éstas, y por uno y otro cualquier género; cercado naturalmente con éstas, y por uno y otro lado, tanto por la 
espalda como por la parte superior cubierto con las mismas, por la parte anterior completamente abierto, y no se cierre de algún modo"24.

Se especifica cómo debe ser la base, la silla, y la altitud del confesonario, la tablilla en que se apoya el confesor, el escabel del penitente, la ventanilla intermedia, la imagen del crucificado, y entre otros pormenores, finalmente, en qué lugar de la iglesia deben colocarse los confesonarios:

"Los confesonarios colóquense por un lado de la iglesia, fuera del ámbito de la capilla mayor, en un lugar abierto y extenso; unos por la región meridional, otros por la septentrional (Fig. 5).

"También en otros lugares de la iglesia, de acuerdo con la proporción de la amplitud y del sitio de la iglesia, con permiso del obispo alguna vez será lícito colocarlos como en ciertas capillas ampliamente extensas, o en su entrada o en el umbral, de tal modo que el confesonario esté dentro de los setos de reja, pero el penitente afuera; por lo cual hágase que con las rejas de la capilla sean apartados los que, concurriendo desordenadamente a la sacra confesión, y demasiado cerca de otro que entonces confiesa sus pecados, fácilmente perturban o al mismo penitente o al confesor"25.

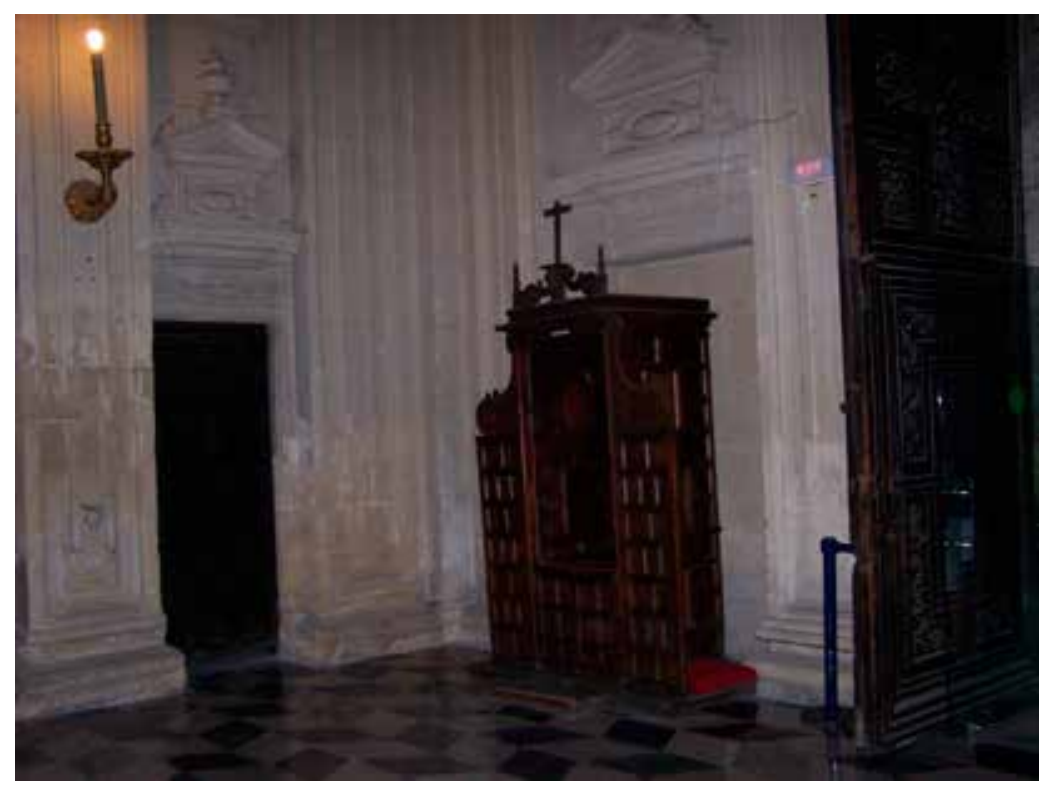

Fig. 5. Confesonario de la iglesia del Sagrario de la catedral de Sevilla.

24 Carlos Borromeo, Instrucciones de la fábrica y del ajuar eclesiásticos, trad. de B. Reyes Coria, México: UNAM, 1985, p. 63. 61-66.

25 Carlos Borromeo, op. cit., p. 66. 
Respecto al número de confesonarios en la iglesia catedral, recomienda tantos cuantos sacerdotes confesores se empleen para las distintas celebraciones. Por otra parte, en las iglesias parroquiales deben colocarse "dos confesonarios para que los varones no estén confusamente mezclados con las mujeres como tampoco muy apretadas entre sí cuando hay una numerosa concurrencia a la sagrada confesión... Pero en la iglesia parroquial en que hay numerosos párrocos, ecónomos, u otros sacerdotes, también coadjutores, que ejercen el deber de oír la confesión, igualmente deberán hacerse otros tantos confesonarios, cuantos en efecto son aquéllos"26 (Fig. 6).Todos estos aspectos llevados a la práctica serán tratados por san Alfonso María de Ligorio en su "Praxis Confessarii" ${ }^{27}$, plasmación práctica de la gran transformación del espacio sagrado tras la aplicación de los decretos tridentinos en la que intervienen también estos olvidados ejemplos de la arquitectura en madera.

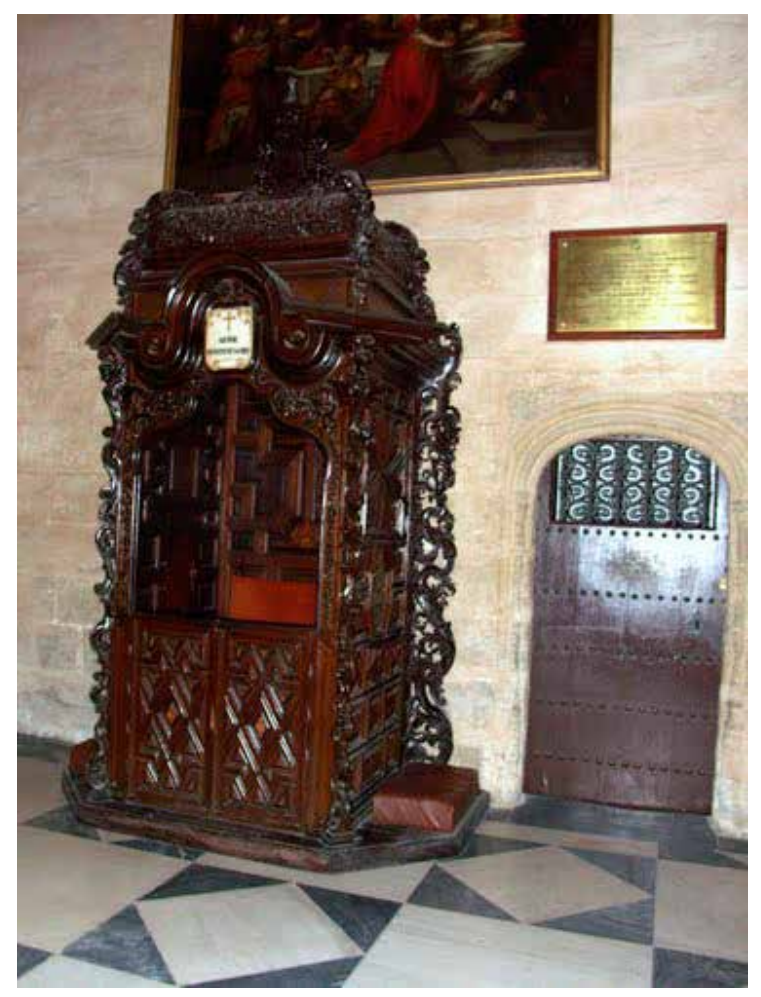

Fig. 6. Confesonario de la catedral de Sevilla.

26 Carlos Borromeo, íbidem, pp. 61-62.

27 Alfonso María de Ligorio, Opera Moralia, IV, Roma, 1912. Véase J. Delumeau,La confesión y el perdón. Las dificultades de la confesión, siglos XIII al XVIII, Madrid: Alianza, 1992, pp. 131-144. 
